Q. WANG, T.-R. LI, L.-Q. LU,* M.-M. LI, K. ZHANG, W.-J. XIAO* (CENTRAL CHINA NORMAL UNIVERSITY, HUBEI AND LANZHOU UNIVERSITY, P. R. OF CHINA)

Catalytic Asymmetric [4 + 1] Annulation of Sulfur Ylides with Copper-Allenylidene Intermediates

J. Am. Chem. Soc. 2016, 138, 8360-8363.

\section{Copper-Catalyzed Asymmetric [4+1] Annulation of Sulfur Ylides}<smiles>C#CC1OC(=O)Nc2ccccc21</smiles><smiles>C[As](CC(=O)O)P(C)(=O)c1ccccc1</smiles>
$\mathrm{Cu}(\mathrm{OTf})_{2}(10 \mathrm{~mol} \%)$ L1 (11 mol\%) DIPEA (3.2 equiv) $R^{1}$<smiles>C#C[C@H]1c2cc[nH+]cc2NN1C=O</smiles>
$\mathrm{dr}>95: 5$

Selected examples:<smiles>C#C[C@H]1c2ccccc2NC1C(=O)c1ccccc1</smiles>
$94 \%$ yield $95 \%$ ee<smiles>C#C[C@H]1c2ccccc2N([AsH3])[C@@H]1C(=O)c1ccc(C#N)cc1</smiles><smiles>C#C[C@H]1c2ccccc2N([As])[C@@H]1C(=O)c1ccc(Cl)cc1</smiles><smiles>C#C[C@H]1c2ccc(Cl)cc2NC1C(=O)c1ccccc1</smiles>

$99 \%$ yield $95 \%$ ee

Plausible mechanism:

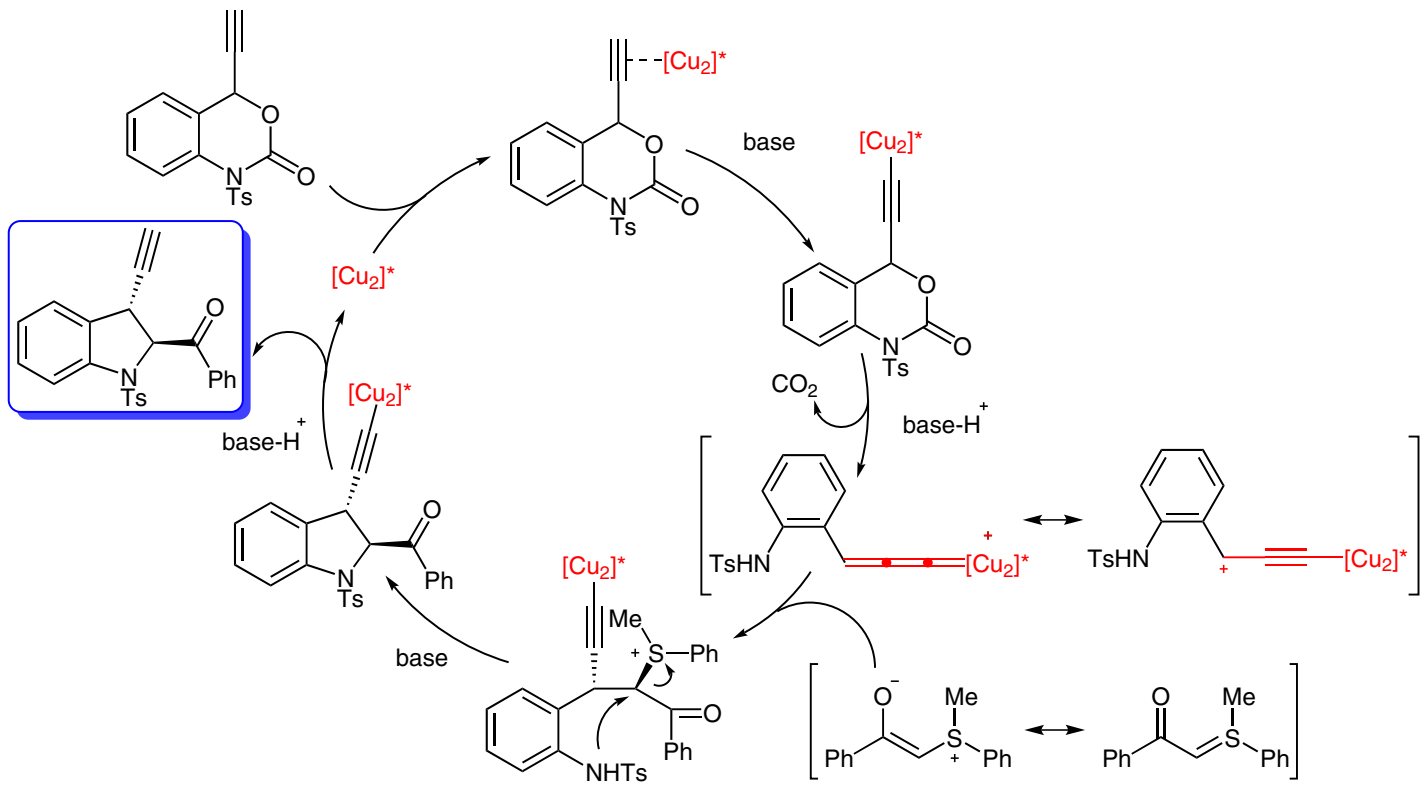

\section{Category}

Metal-Catalyzed Asymmetric

Synthesis and

Stereoselective

Reactions

\section{Key words}

[4+1] annulation

sulfur ylides

copper catalysis

indolines

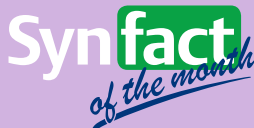

Significance: The authors report a copper-catalyzed asymmetric [4+1] cycloaddition by trapping copper-allenylidene dipolar intermediates with sulfur ylides. A variety of chiral indolines were obtained with high stereoselectivities ( $\leq 98 \%$ ee and $d r>95: 5)$.

SYNFACTS Contributors: Hisashi Yamamoto, Masahiro Sai Synfacts 2016, 12(09), 0925 Published online: 18.08.2016 Dol: 10.1055/s-0035-1562766; Reg-No.: H10416SF
Comment: This reaction affords an opportunity for the ready synthesis of chiral indoline products and related cycloadducts with high stereoselectivities. Mechanistic studies suggest that this reaction is a sequential process that involves decarboxylative propargylation $/ S_{N} 2$ reactions promoted by binuclear copper complexes. 